
Pathophysiology of Haemostasis and Thrombosis

Received: February 20, 2002

Accepted in revised form: J une 13, 2002

\title{
Hemostasis and Fibrinolysis Factors in First-Degree Relatives of Patients with Type 2 Diabetes without Hypertension
}

\author{
A. Trifiletti A. Lasco R. Scamardi M. Cincotta A. Gaudio N. Barbera \\ N. Frisina
}

Department of Internal Medicine, University of Messina, Italy

\section{Key Words}

Diabetes $\cdot$ Hemostatic system $\cdot$ Hypertension .

Insulin resistance $\cdot$ Non-insulin-dependent diabetes

\begin{abstract}
First-degree relatives of type 2 diabetic patients with or without a family history of hypertension are at increased risk for cardiovascular diseases. The aim of this study was to verify some possible hemostatic alterations in first-degree relatives of type 2 diabetic, normotensive and hypertensive patients. In 78 non-diabetic, normotensive first-degree relatives of type 2 diabetic patients (47 without a family history of hypertension and 31 with a family history of hypertension) and in 36 normoglycemic, normotensive subjects with no family history of hypertension, we evaluated plasma levels of fasting glucose and insulin, tissue-type plasminogen activator (t-PA), plasminogen activator-inhibitor (PAI-1), D-dimer (DD) and prothrombin fragment $1+2(\mathrm{~F} 1+2)$. Insulin resistance, calculated by the HOMA model, and plasma levels of t-PA and PAI-1 were significantly higher in relatives of diabetics compared to controls. As far as the thrombin activation indexes are concerned, we detected a significant increase in DD and $\mathrm{F} 1+2$ in relatives of diabetics with hypertension compared to other study sub-
\end{abstract}

\section{KARGER}

Fax +41613061234

E-Mail karger@karger.ch

www.karger.com

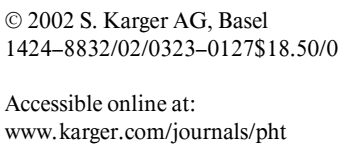

jects. In conclusion, our data indicate that familial predisposition may influence the hemostatic system in firstdegree relatives of diabetic and/or hypertensive patients.

Copyright $@ 2002$ S. Karger AG, Basel

\section{Introduction}

Cardiovascular disease is the major cause of morbidity and mortality in patients with non-insulin-dependent diabetes mellitus. Diabetes patients have a higher risk of developing cardiovascular complications and a poorer outcome from cardiovascular events than patients without diabetes [1-3]. Although part of this increased risk may be related to glycemic control, other factors are also involved, in particular changes in the hemostatic system. In cases of vascular damage, fibrin deposition may be important in the development of atherosclerotic lesions after occlusive thrombus formation [4-6]. In diabetic patients, a procoagulant state is observed, which could contribute to the risk of premature cardiovascular events. In particular, alterations in the plasma concentrations of coagulation and fibrinolysis factors are considered the link between diabetes mellitus and cardiovascular complications [7-9]. Also, in a hypertensive state, changes in
Aldo Trifiletti, MD

Via Monsignor D'Arrigo 23

I-98121 Messina (Italy)

Tel +390902936528, Fax +390902935162

E-Mail Aldo.Trifiletti@unime.it 
the balance between hemostatic and antithrombotic processes, inducing a prethrombotic state, may contribute to hypertensive vascular complications [10-12].

The offspring of patients with diabetes have an increased risk of developing the same disease [13] and others [14-19]. The aim of this study was to determine whether there is a possible hemostatic impairment in first-degree relatives of type 2 diabetic patients regarding D-dimer (DD), tissue-type plasminogen activator (t-PA), plasminogen activator-inhibitor (PAI-1) and prothrombin fragment $1+2(\mathrm{~F} 1+2)$ levels and to analyze the influence of the presence/absence of a family history of hypertension on the hemostatic system.

\section{Patients and Methods}

\section{Subjects}

We studied a total of 100 subjects, recruited from first-degree relatives of consecutive type 2 diabetic patients admitted to the Department of Internal Medicine of the Messina University from February to June 2000. After having obtained their written informed consent, we performed a complete checkup and an oral glucose tolerance test (75 g) on each of them, according to WHO criteria [20]. Subjects with impaired glucose tolerance $(n=12)$, diabetes mellitus $(n=7)$ and hypertension $(n=3)$ were excluded from the study. The remaining subjects (78) were divided into two groups on the basis of the presence/absence of a family history of hypertension: group 1 (without a family history of hypertension) consisted of 47 subjects (mean age $29.5 \pm 7.8$ years) and group 2 (with a family history of hypertension) consisted of 31 subjects (mean age $31.4 \pm 8.5$ years).

In addition, after having obtained their written informed consent, we recruited 40 volunteers matched for age and body mass index to the first two groups from the School of Nurses, Messina. After a complete checkup and having performed an oral glucose tolerance test, subjects with hypertension, a family history of hypertension, impaired glucose tolerance or diabetes mellitus were excluded from the study. The remaining 36 normoglycemic, normotensive subjects were studied as controls and assigned to group 3. None of the subjects of the three groups had known diseases or were taking any drugs.

The study protocol was approved by the Ethic Committee of the University of Messina School of Medicine.

\section{Blood Sampling and Assay Methods}

Blood samples were obtained by antecubital venipuncture; blood was drawn between 8 a.m. and 11 a.m. after an overnight fast and a 10-min rest. The first 4-5 $\mathrm{ml}$ were discarded. Blood was mixed (1:10, $\mathrm{v} / \mathrm{v})$ with $0.13 \mathrm{~mol} / \mathrm{l}$ trisodium citrate, placed directly into refrigerated vacutainers, immediately placed on ice, centrifuged within a few minutes at 2,000 $\mathrm{g}$ for $20 \mathrm{~min}$ at $4^{\circ} \mathrm{C}$ and frozen at $80^{\circ} \mathrm{C}$ for about 3 months until assayed. Plasma levels of t-PA, PAI-1, DD and prothrombin $\mathrm{F} 1+2$ were measured by enzyme-linked immunosorbent assays. In particular, t-PA was evaluated by Asserachrom t-PA (Diagnostica Stago, Asnières-sur-Seine, France, normal range 1-12 ng/ml), PAI-1 by Asserachrom PAI-1 (Diagnostica Stago, normal range 4$43 \mathrm{ng} / \mathrm{ml}$ ), DD by Asserachrom D-Dimer (Diagnostica Stago, normal values $<500 \mathrm{ng} / \mathrm{ml}$ ) and $\mathrm{F} 1+2$ by Enzygnost $\mathrm{F} 1+2$ micro (Behringwerke, Germany, normal range 0.2-1.1 nmol/l). A double sample was evaluated for each subject.

Fasting plasma levels of glucose were determined by a glucose oxidase method (Boehringer Mannheim, Marburg, Germany, normal range 4.2-6.4 nmol/l). Fasting insulin values were evaluated by radioimmunoassay (Abbott Laboratories, Abbott Park, Ill., USA, normal range $5-25 \mu \mathrm{U} / \mathrm{ml}$ ). Values for relative insulin resistance were estimated using the computer-solved homeostasis model assessment (HOMA) which assumes that normal weight subjects aged less than 35 years have $100 \%$ pancreatic islet $\beta$-cell function and an insulin resistance of one [21].

Blood pressure was measured in the right arm with subjects sitting, under standardized conditions and to the nearest $2 \mathrm{~mm} \mathrm{Hg}$. Systolic and diastolic blood pressure were calculated from the mean of three readings. Hypertension was defined as a systolic blood pressure $\geq 140 \mathrm{~mm} \mathrm{Hg}$ and/or a diastolic blood pressure $\geq 90 \mathrm{~mm} \mathrm{Hg}$.

\section{Statistical Analysis}

Data are shown as means \pm SD. One-way ANOVA and unpaired $t$ test were used for comparison of mean values between two groups. Differences with a value of $\mathrm{p}<0.05$ were considered significant.

\section{Results}

The basic characteristics of all subjects are shown in table 1 . There were no significant differences in mean age, gender, body mass index or smoking habits among the groups.

The study parameters are shown in table 2 . There were no significant differences between these groups for values of systolic and diastolic blood pressure. Plasma insulin levels were statistically higher in groups 1 and 2 than in group 3 , and in group 2 compared to group 1. Fasting plasma levels of glucose were statistically higher only in group 2. Insulin resistance, calculated by the HOMA model, was however significantly higher in both groups of relatives of diabetics compared to controls, and was above the levels that the model assumes for healthy 30 -year-old subjects. In groups 1 and 2 (relatives of diabetics), t-PA and PAI-1 were significantly higher than in controls. As far as the thrombin activation indexes are concerned, we detected a significant increase in DD and F1+2 in group 2 compared to groups 1 and 3 .

\section{Discussion}

The relationship between insulin resistance and the hemostatic system is extremely important in understanding the increased cardiovascular risk to which diabetic patients are prone. However, it is even more interesting that the relatives of diabetics display a series of hemostat- 
Table 1. Basic characteristics of the first-degree relatives of diabetic patients without (group 1) and with a family history of hypertension (group 2) and the controls (group 3)

\begin{tabular}{lllll}
\hline & Group 1 & Group 2 & Group 3 & p value \\
\hline $\mathrm{n}$ & 47 & 31 & 36 & \\
Age, years & $31.0 \pm 9.1$ & $31.4 \pm 8.5$ & $29.5 \pm 7.8$ & $>0.05$ \\
Gender, males/females & $21 / 26$ & $17 / 14$ & $23 / 13$ & $>0.05$ \\
Body mass index, kg/m ${ }^{2}$ & $24.9 \pm 0.6$ & $24.7 \pm 0.5$ & $24.8 \pm 0.4$ & $>0.05$ \\
Current smokers, \% & $15(31.9)$ & $12(38.8)$ & $16(34.8)$ & $>0.05$
\end{tabular}

Data are expressed as means $\pm \mathrm{SD}$.

\begin{tabular}{lccr}
\hline & Group 1 & Group 2 & Group 3 \\
\hline $\mathrm{n}$ & 47 & 31 & 36 \\
Insulin, $\mu \mathrm{U} / \mathrm{ml}$ & $11.7 \pm 0.3^{*}$ & $12.0 \pm 0.3^{*, * *}$ & $10.1 \pm 0.2$ \\
Glucose, nmol/1 & $4.1 \pm 0.3$ & $4.2 \pm 0.2^{*}$ & $4.1 \pm 0.1$ \\
Insulin resistance (HOMA model) & $2.1 \pm 0.3^{*}$ & $2.2 \pm 0.2^{*}$ & $1.7 \pm 0.2$ \\
Systolic blood pressure, mm Hg & $124.2 \pm 4.0$ & $122.0 \pm 4.8$ & $122.6 \pm 5.2$ \\
Diastolic blood pressure, mm Hg & $74.2 \pm 4.9$ & $76.6 \pm 6.2$ & $76.6 \pm 5.8$ \\
t-PA, ng/ml & $10.1 \pm 4.0^{*}$ & $10.8 \pm 3.9^{*}$ & $6.8 \pm 3.5$ \\
PAI-1, ng/ml & $28.1 \pm 7.9^{*}$ & $27.5 \pm 8.1^{*}$ & $21.2 \pm 7.8$ \\
DD, ng/ml & $250.5 \pm 64.3$ & $325.4 \pm 65.0^{*, * *}$ & $232.0 \pm 58.7$ \\
F1+2, nmol/l & $0.21 \pm 0.06$ & $0.34 \pm 0.05^{*, * *}$ & $0.19 \pm 0.07$ \\
\hline
\end{tabular}

${ }^{*} \mathrm{p}<0.05$ vs. group $3,{ }^{* *} \mathrm{p}<0.05$ vs. group 1 . Data are means \pm SD.
Table 2. Evaluated parameters in first-degree relatives of diabetic patients without (group 1) and with a family history of hypertension (group 2) and controls (group 3) ic impairments, even if these subjects are not affected by clinical diabetes mellitus or vascular diseases.

It is known that the family history is very important in the pathogenesis of type 2 diabetes mellitus. In fact, 22\% of the first-degree relatives of diabetic patients enrolled in the study were excluded because they were affected by impaired glucose tolerance or diabetes mellitus. The remaining subjects presented higher insulin resistance than controls, meaning that some of them might develop diabetes mellitus in the future, in accordance with previous studies [13].

Our data show that non-diabetic first-degree relatives of diabetic patients have higher levels of t-PA and PAI-1 than controls. Previous studies found higher levels of PAI-1 in the offspring of diabetics and suggested that those increased levels could fully be explained by increased insulin resistance, but this alteration was considered in part independent of differences in the features of insulin resistance, age, sex, smoking habits and PAI-1 promoter genotype [15].

The impact of a family history of hypertension is explained by the higher levels of thrombin activation indexes that we found in relatives of hypertensive diabetic subjects compared to relatives of normotensive diabetics.
These data confirm the results of other clinical observations that showed activated coagulation even in the presence of a lesser degree of glucose intolerance [14] and increased insulin resistance in first-degree relatives of type 2 diabetic patients $[22,23]$. The fact that DD and F1+2 levels in subjects with a family history of type 2 diabetes mellitus associated with hypertension are higher than in relatives of diabetics without a family history of hypertension seems to suggest that blood coagulation in these subjects is genetically influenced.

On the basis of these findings, it seems correct to focus on the diagnosis of the insulin resistance syndrome in relatives of diabetics and on its treatment at an early stage, before macroangiopathy has started or reached a clinically manifest level.

In conclusion, our data indicate that familial predisposition may influence the relationship between insulin resistance and the hemostatic system, an effect that may contribute to the clinical importance of the metabolic syndrome. Besides, in light of our results, a family history of hypertension, with the consequent increase in thrombin activation indexes, seems to represent an additional factor for increased cardiovascular risk. 


\section{References}

1 Standl E: Cardiovascular risk in type 2 diabetes. Diabetes Obes Metab 1999;1(suppl 2):S24-S36.

2 Bloomgarden ZT: Cardiovascular diseases in type 2 diabetes. Diabetes Care 1999;22:1739_ 1744.

3 Wingard DL, Berrett-Connor E: Heart disease and diabetes; in Harris MI (ed): Diabetes in America, ed 2. Washington, US Government Printing Office, 1995, pp 429-448.

4 Baumgartner HR, Sakariassen KS: Factors controlling thrombus formation on arterial lesions. Ann NY Acad Sci 1985;454:162-176.

5 Schwarz CJ, Valente AJ, Kelley JL: Thrombosis and development of atherosclerosis: Rokitansky revisited. Semin Thromb Hemost 1988; 14:189-195

6 Davies MJ, Thomas A: Thrombosis and acute coronary artery lesions in sudden cardiac ischaemic death. N Engl J Med 1984;310:11371140.

7 Carmassi F, Morale M, Puccetti R, De Negri F, Monzani F, Navalesi R, Mariani G: Coagulation and fibrinolytic system impairment in insulin dependent diabetes mellitus. Thromb Res 1992;67:643-654.

8 Kario K, Matsuo T, Kobayashi H, Matsuo M, Sakata T, Miyata T: Activation of tissue factorinduced coagulation and endothelial cell dysfunction in non-insulin-dependent diabetic patients with microalbuminuria. Arterioscler Thromb Vasc Biol 1995; 15:1114-1120.

9 Kwaan HC: Changes in blood coagulation, platelet function and plasminogen-plasma system in diabetes. Diabetes 1992;41(suppl 2):3235 .
10 Gomi T, Ikeda T, Yuhara M, Sakurai J, Nakayama D, Ikegami F: Plasma beta-thromboglobulin to platelet factor 4 ratios as indices of vascular complications in essential hypertension. J Hypertens 1988;6:389-392.

11 Vaziri ND, Smith DH, Winer RL, Weber MA, Gonzales EC, Neutel JM: Coagulation and inhibitory and fibrinolytic proteins in essential hypertension. J Am Soc Nephrol 1993;4:222228.

12 Van Wersch JW, Rompelberg-Lahaye J, Lustermans FA: Plasma concentration of coagulation and fibrinolysis factors and platelet function in hypertension. Eur $\mathbf{J}$ Clin Chem Clin Biochem 1991;29:375-379.

13 Shaw JT, Levy JC, Turner RC: The relationship between the insulin resistance syndrome and insulin insensitivity in the first-degree relatives of subjects with non-insulin dependent diabetes mellitus. Diabetes Res Clin Pract 1998;42:91-99.

14 Fernandez-Castaner M, Camps I, FernandezReal JM, Domenech P, Martinez-Brotons F: Increased prothrombin fragment $1+2$ and $\mathrm{D}$ dimer in first-degree relatives of type 2 diabetic patients. Acta Diabetol 1996;33:118-121.

15 Mansfield MW, Stickland MH, Grant PJ: PAI1 concentrations in first-degree relatives of patients with non-insulin-dependent diabetes: Metabolic and genetic associations. Thromb Haemost 1997;77:357-361.

16 Endre T, Mattiasson I, Berntorp E, Berglund G, Hulten UL: Coagulation and fibrinolytic factors in normotensive hypertension-prone men. J Hypertens 1996;14:629-634.
17 Andersen UB, Dige-Petersen H, Frandsen EK, Ibsen H, Volund A: Basal insulin-level oscillations in normotensive individuals with genetic predisposition to essential hypertension exhibit an irregular pattern. J Hypertens 1997;15: 1167-1173.

18 Grandi AM, Gaudio G, Fachinetti A, Zanzi P, Bianchi L, Ceriani L, Guasti L, Venco A: Influence of family history of hypertension on insulin sensitivity in lean and obese hypertensive subjects. Eur J Clin Invest 1997;27:774779.

19 Valek J, Valkova L, Vlasakova Z, Topinka V: Increased fibrinogen levels in the offspring of hypertensive men. Relation with hyperinsulinemia and the metabolic syndrome. Arterioscler Thromb Vasc Biol 1995;15:2229-2233.

20 WHO Study Group on Diabetes Mellitus: WHO Technical Report Series No. 727. Geneva, World Health Organization, 1985.

21 Matthews DR, Hosker JP, Rudenski AS, Naylor BA, Treacher DF, Turner RC: Homeostasis model assessment: Insulin resistance and $\beta$-cell function from fasting plasma glucose and insulin concentrations in men. Diabetologia 1985; 28:412-419.

22 Forsblom CM, Eriksson JG, Ekstrand AV, Teppo AM, Taskinen MR, Groop LC: Insulin resistance and abnormal albumin excretion in non-diabetic first-degree relatives of patients with NIDDM. Diabetologia 1995;38:363-369.

23 Beck-Nielsen H, Henriksen JE, Alford F, Hother-Nielson O: In vivo glucose metabolism, insulin secretion and, insulin action in Europids with non-insulin-dependent diabetes mellitus (NIDDM) and their first-degree relatives. Diabet Med 1996;19(9 suppl 6):S78-S84. 